\title{
Apoptosome dependent caspase-3 activation pathway is non-redundant and necessary for apoptosis in sympathetic neurons
}

\author{
$\mathrm{KM}_{\text {Wright }}{ }^{1,3}$, AE Vaughn ${ }^{2,3}$ and M Deshmukh ${ }^{\star, 1,2,3}$
}

\begin{abstract}
Although sympathetic neurons are a well-studied model for neuronal apoptosis, the role of the apoptosome in activating caspases in these neurons remains debated. We find that the ability of sympathetic neurons to undergo apoptosis in response to nerve growth factor (NGF) deprivation is completely dependent on having an intact apoptosome pathway. Genetic deletion of Apaf-1, caspase-9, or caspase-3 prevents apoptosis after NGF deprivation, and importantly, allows these neurons to recover and survive long-term following readdition of NGF. The inability of caspase-3 deficient sympathetic neurons to undergo apoptosis is particularly striking, as apoptosis in dermal fibroblasts and cortical neurons proceeds even in the absence of caspase-3. Our results show that in contrast to dermal fibroblasts and cortical neurons, sympathetic neurons express no detectable levels of caspase-7. The strict requirement for an intact apoptosome, coupled with a lack of effector caspase redundancy, provides sympathetic neurons with a markedly increased control over their apoptotic pathway.
\end{abstract}

Cell Death and Differentiation (2007) 14, 625-633. doi:10.1038/sj.cdd.4402024; published online 25 August 2006

Apoptosis, a form of programmed cell death, is a critical component of normal organism development. The major molecular events that occur during apoptosis have been identified by many elegant biochemical studies, using both cell free systems and cell lines. ${ }^{1}$ However, differences in the regulation of this pathway exist in various primary cells that are of physiological and pathological importance. The nervous system provides an ideal system in which to study developmental apoptosis, as a clear role for apoptosis for defining appropriate cell number and correct innervation of target organs by axons, has been described in both the central and the peripheral nervous system. ${ }^{2}$ However, an understanding of the exact mechanisms by which apoptosis occurs in the developing nervous systems remains incomplete.

Apoptosis is orchestrated by the activation of caspases, a family of cysteine proteases present as inactive zymogens in cells. ${ }^{3}$ Caspases can be classified as either initiator caspases, identified by their large prodomain (e.g., caspase-8, caspase9), or executioner caspases (e.g., caspase-3, caspase-7). Initiator caspases are activated by recruitment to large multimeric complexes by their prodomains in response to apoptotic stimuli. ${ }^{4}$ Once the initiator caspases become activated, they cleave the executioner caspases, thereby exposing their catalytic active site. ${ }^{5}$ Active executioner caspases proceed to cleave a variety of substrates, including DNA fragmentation factors and cytoskeletal elements, resulting in the ordered destruction of the cell.

Activation of caspases by the intrinsic pathway of apoptosis, which is important for developmental apoptosis in the nervous system, is dependent on the formation of a large multimeric complex termed the apoptosome. ${ }^{6}$ The apoptosome-mediated activation of caspases is initiated by the release of cytochrome $c$ from the mitochondria, a process that is regulated by interactions between the antiapoptotic and proapoptotic members of the Bcl-2 family of proteins. Once cytochrome $c$ is released into the cytosol, it binds to the adaptor protein Apaf-1 to form the apoptosome. Procaspase9 molecules are then recruited to this complex, resulting in the activation of caspase- 9 . Activated caspase- 9 in turn activates the effector caspase-3 and caspase-7 through cleavage. If left unchecked, the activation of caspases represents an irreversible event that leads to the inevitable demise of the cell. However, active caspases can be regulated by their endogenous inhibitors, members of the family of the inhibitor of apoptosis proteins (IAPs). ${ }^{7}$ These ubiquitously expressed inhibitors function by binding to the catalytic sites of activated caspases, occluding their activity. IAPs can be negatively regulated by the proteins Smac and HTRA2, which function by binding to and sequestering the IAPs, thereby preventing them from binding caspases and allowing apoptosis to proceed. $^{4}$

The sympathetic neurons of the superior cervical ganglia are a well-studied model of developmental apoptosis. During early postnatal development, these postmitotic neurons are acutely dependant on target-derived nerve growth factor (NGF) for their survival. ${ }^{8}$ During this process, approximately $50 \%$ of sympathetic neurons die by apoptosis in vivo as a result of receiving insufficient quantities of $\mathrm{NGF}^{2}$ This process can be recapitulated in vitro, as cultured sympathetic neurons deprived of NGF proceed through a synchronous

${ }^{1}$ Curriculum in Neurobiology, University of North Carolina, Chapel Hill, NC 27599, USA; ${ }^{2}$ Department of Cell and Developmental Biology, University of North Carolina, Chapel Hill, NC 27599, USA and ${ }^{3}$ Neuroscience Center, University of North Carolina, Chapel Hill, NC 27599, USA

*Corresponding author: M Deshmukh, University of North Carolina, 7109E Neuroscience Research Building, Box 7250, 105 Mason Farm Road, Chapel Hill, NC 27599, USA. Tel: 919843 6004; Fax: 919966 1050; E-mail: mohanish@med.unc.edu

Keywords: apoptosis; cytochrome $C$; Apaf-1; caspase; neurons; apoptosome

Abbreviations: NGF, nerve growth factor; IAPs, inhibitor of apoptosis proteins; XIAP, X-linked inhibitor of apoptosis proteins; P0, postnatal day 0

Received 13.2.06; revised 10.7.06; accepted 17.7.06; Edited by GP Gasic; published online 25.8.06 
pathway culminating in apoptosis, which can be effectively blocked with broad spectrum caspase inhibitors. ${ }^{9,10}$ This pathway is critically dependent on the release of cytochrome $c$ from the mitochondria, as genetic deletion of the proapoptotic Bcl-2 family member Bax completely prevents cytochrome $c$ release and subsequent apoptosis induced by NGF withdrawal in sympathetic neurons. ${ }^{8}$ Likewise, NGF deprivation induced apoptosis is blocked when sympathetic neurons are microinjected with neutralizing antibodies to cytochrome $c .^{11}$ These results suggest that NGF deprivation induced apoptosis in sympathetic neurons proceeds through the cytochrome $c$-dependent apoptosome pathway.

In contrast, some studies have proposed that caspase-2 activation, and not caspase- 9 activation, is the primary mechanism of apoptosis in sympathetic neurons following NGF deprivation. ${ }^{12}$ These experiments utilized acute knockdown of caspase-2 with antisense RNA or inhibition of caspase-2 activity with dominant-negative constructs and showed protection of sympathetic neurons after NGF deprivation. ${ }^{12-14}$ However, these results are conflicted by studies using neurons isolated from caspase- 2 deficient mice, which show no protection from apoptosis following NGF deprivation. ${ }^{12,15,16}$

To specifically assess the importance of the apoptosome pathway in regulating apoptosis in postmitotic sympathetic neurons, we examined neurons isolated from mice genetically deficient in Apaf-1, caspase-9, or caspase-3. Our results show that sympathetic neurons isolated from these mice demonstrate remarkable protection with long-term recoverability from NGF deprivation induced apoptosis. In particular, we compared the phenotype of caspase-3 deficient sympathetic neurons with dermal fibroblasts and cortical neurons isolated from the same mice. We find that in contrast to both cortical neurons and dermal fibroblasts, which express partial redundancy between caspase-3 and caspase-7, sympathetic neurons do not express detectable levels of caspase-7 and therefore are completely dependent on caspase-3 for apoptosis. These data show that the apoptosome pathway is required for sympathetic neuronal apoptosis and highlight cell type specific differences in apoptosis execution.

\section{Results}

NGF deprivation induced apoptosis in sympathetic neurons requires Apaf-1, caspase-9, and caspase-3. To determine the critical role of Apaf-1, caspase-9, and caspase-3 in mediating apoptosis in postmitotic neurons, we examined the ability of sympathetic neurons isolated from mice deleted for Apaf-1, caspase-9, or caspase-3 to undergo apoptosis after trophic factor deprivation. The original 129S1/ SvimJ (129) strain of Apaf-1, caspase-9, and caspase-3 deficient mice were marked by exencephaly and embryonic lethality, presumably caused by the reduction of apoptosis in mitotic neural precursors. ${ }^{17,18}$ This embryonic lethality precluded examination of postmitotic sympathetic neurons during their normal period of developmental cell death, which occurs during the first postnatal week. However, backcrossing of these mice to a C57BL/6J (B6) background has been shown to reduce the occurrence of exencephaly, allowing these mice to routinely be born and survive long-term. ${ }^{19-21}$
Sympathetic neurons were therefore isolated from postnatal day 0 (P0) wild-type (WT) mice or mice lacking Apaf-1, caspase- 9 , or caspase-3 on the B6 strain background. These neurons were maintained in the presence of NGF for 5 days, following which they were deprived of NGF and survival was assessed by morphology at multiple time points. WT neurons deprived of NGF exhibited apparent characteristic morphology associated with apoptosis by $24 \mathrm{~h}$, including cell shrinkage and degeneration of neurites and cell bodies (Figure 1a, b). In contrast, neurons from Apaf-1, caspase-9, and caspase-3 null littermates were completely resistant to NGF deprivation induced apoptosis, as greater than $80 \%$ of neurons remained viable and maintained intact phase bright cell bodies even $96 \mathrm{~h}$ after NGF deprivation (Figure 1a, b).

In actively dividing mitotic cells, caspase inhibition or genetic deletion of Apaf-1 or caspase- 9 has been shown to confer short-term protection in response to apoptotic stimuli. However, when long-term survival of these cells is assessed by examining their clonogenic potential, blockade of the apoptotic pathway downstream of cytochrome $c$ release by inhibition of caspases or by deletion of Apaf- 1 or caspase- 9 was unable to prevent the eventual death of these cells. ${ }^{22-24}$ These results implicate the release of cytochrome $c$ from the mitochondria as the commitment point for death in mitotic cells.

To assess the long-term survival of sympathetic neurons from Apaf- 1 , caspase- 9 , and caspase- 3 null mice in a rigorous manner, we examined their ability to recover from NGF deprivation following the release of cytochrome $c$. Following $24 \mathrm{~h}$ of NGF deprivation, approximately $90 \%$ of WT, Apaf-1, caspase-9, and caspase-3 null sympathetic neurons had released cytochrome $c$ (Figure 1c), ${ }^{25,26}$ and the WT neurons had already died by apoptosis (Figure 1a). To assess longterm recoverability following the release of cytochrome $c$, cultures were deprived of NGF for 24-30 h, following which NGF was restored to the cultures and survival was assessed following 7 days. WT neurons that were deprived of NGF exhibited no long-term survival following 7 days of NGF readdition. In contrast, Apaf-1, caspase-9, and caspase-3 deficient sympathetic neurons exhibited significant long-term survival following 7 days of NGF re-addition (Figure 1d). Taken together, these data indicate that Apaf-1, caspase- 9 , and caspase- 3 are important components of the apoptotic pathway in trophic factor deprived sympathetic neurons, and that neurons lacking these proteins maintain their capacity to recover and survive long term.

Caspase-3 deficiency protects sympathetic neurons but not dermal fibroblasts from direct activation of the apoptosome. To compare the importance of Apaf-1, caspase-9, and caspase-3 specifically in postmitotic neurons and mitotic fibroblasts, we directly activated the apoptosome pathway by cytosolic microinjection of cytochrome $c$. Single-cell microinjection of cytochrome $c$ allows us to bypass any differences upstream of the mitochondria between these two cell types and to focus directly on assessing the apoptosome function. As we have previously demonstrated, injection of cytochrome $c$ alone is insufficient to induce apoptosis in sympathetic neurons due to strict inhibition of caspases by X-linked inhibitor 
a
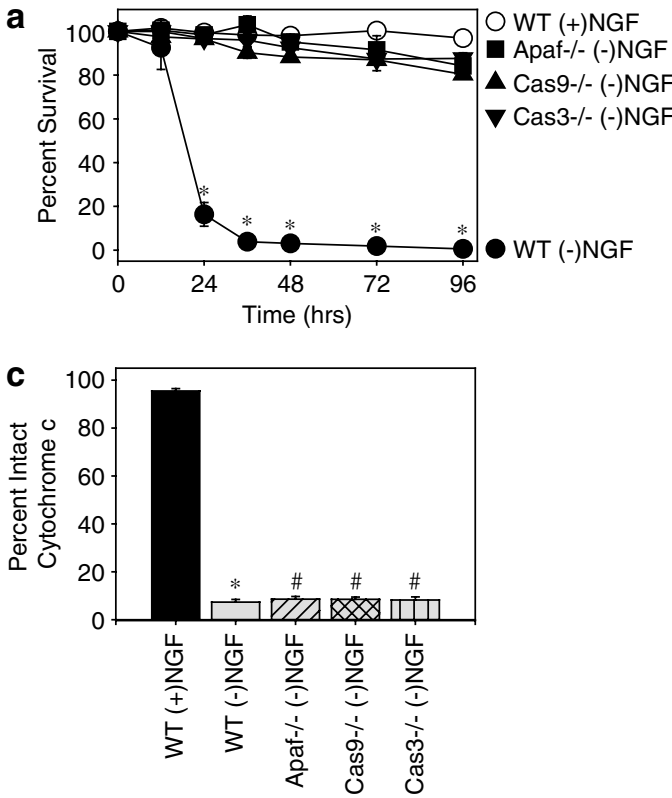

d

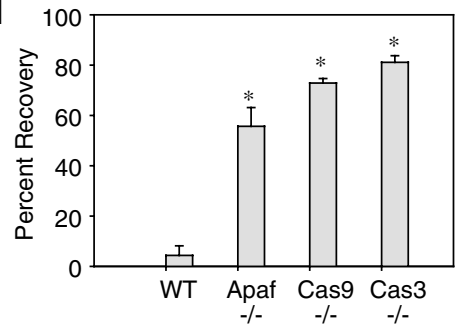

b
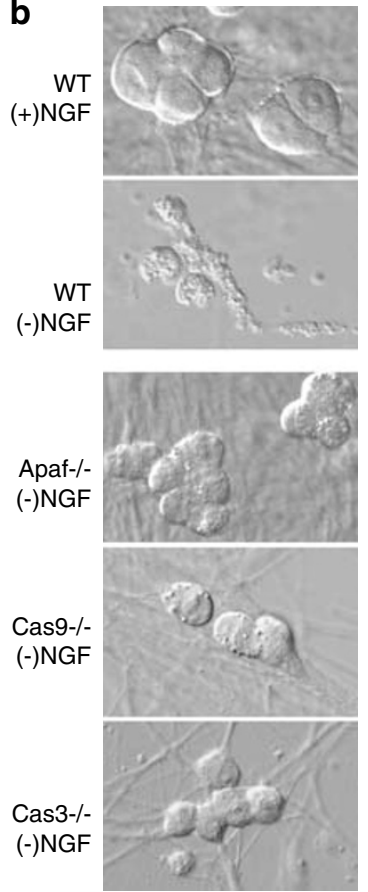

Figure 1 Genetic deletion of Apaf-1, Caspase-9, or Caspase-3 prevents apoptosis of NGF-deprived sympathetic neurons. (a) P0 sympathetic neurons from WT, Apaf-1-I-, Caspase-9-/ - and Caspase-3-I- mice were cultured in the presence of NGF for 5 days. Cells were washed twice and re-fed with NGF free media. Cell viability, determined by the presence of intact, phase bright cell bodies, was assessed at the indicated timepoints. Data are means \pm S.E.M. ${ }^{*} P<0.005$ for WT NGF deprived condition (-NGF) relative to all other conditions. (b) Representative differential interference contrast (DIC) photomicrographs of WT, Apaf-1-/-, Caspase-9-/-, and Caspase-3-/sympathetic neurons maintained or deprived of NGF for $24 \mathrm{~h}$ as indicated in (a). (c) Sympathetic neurons from WT, Apaf-1-1-, Caspase-9-1- and Caspase-3-/- mice were maintained in NGF or deprived of NGF for $24 \mathrm{~h}$ and the percentage of cells with intact mitochondrial cytochrome $c$ was determined by immunofluorescence. Data are mean \pm S.E.M. ${ }^{*} P<0.001$ for WT NGF deprived neurons relative to WT NGF maintained neurons. ${ }^{\#} P=$ not significant for Apaf-1-l-, Caspase-9-/-, and Caspase-3-INGF deprived neurons relative to WT NGF deprived neurons. (d) Long-term recoverability of NGF-deprived sympathetic neurons was determined by depriving neurons of NGF for 24-30 $\mathrm{h}$ as indicated in (a) and then adding back NGF containing media. Cell viability was then assessed 7 days after readdition of NGF containing media. Data are mean \pm S.E.M. ${ }^{*} P<0.01$ for Apaf-1-/-, Caspase-9-/-, and Caspase-3-/- recoverability relative to WT

of apoptosis proteins $(\mathrm{XIAP}) .^{27}$ However, injection of cytochrome $c$ and Smac together is sufficient to overcome XIAP and induce apoptosis in WT sympathetic neurons ${ }^{27,28}$ (Figure 2a, b). In contrast, sympathetic neurons isolated from Apaf-1 and caspase-9 knockout mice were completely resistant to coinjection of cytochrome $c$ and Smac, even up to $24 \mathrm{~h}$ following injection (Figure $2 \mathrm{a}, \mathrm{b}$ ). As anticipated, primary dermal fibroblasts isolated from WT mice died rapidly upon injection of cytochrome $c$. Co-injection of cytochrome $c$ and Smac did not further increase the rate of apoptosis in dermal fibroblasts, indicating that their apoptosome pathway is not under strict IAP-mediated regulation. Significantly, neither injection of cytochrome $c$ alone nor co-injection of cytochrome $c$ and Smac in dermal fibroblasts isolated from Apaf-1 and caspase- 9 null mice induced any significant apoptosis (Figure $2 \mathrm{c}, \mathrm{d}$ ). These results show that Apaf- 1 and caspase- 9 are essential for apoptosis induced by cytochrome $c$ in both mitotic fibroblasts and postmitotic sympathetic neurons, indicating there are no proteins that compensate for the loss of either Apaf-1 or caspase- 9 in these cells.

Downstream of caspase-9 redundancy at the level of effector caspases has been reported. In particular, caspase7 has been shown to be able to functionally compensate for the loss of caspase 3 in the developing cortex of caspase-3 null B6 mice. ${ }^{20}$ However, our data indicate that deletion of caspase-3 alone inhibits trophic factor deprivation induced apoptosis in sympathetic neurons (Figure 1), arguing against functional redundancy at the level of executioner caspases in sympathetic neurons.

To directly assess functional redundancy of executioner caspases in intact cells, we asked whether injection of cytochrome $c$ is sufficient to induce apoptosis in primary fibroblasts and sympathetic neurons isolated from caspase-3 deficient mice. Consistent with our observations in the context of NGF deprivation, coinjection of cytochrome $c$ and Smac 
a

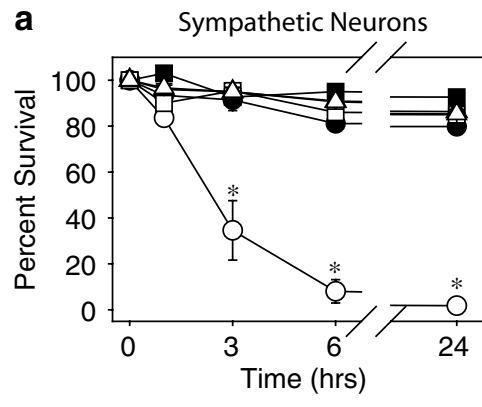

- WT cyto $c$

- - WT cyto $c+$ Smac

$\rightarrow$ - Apaf -/- cyto $c$

$-\square-$ Apaf $-/-$ cyto $c+$ Smac

- Cas9 -/- cyto $c$

$\triangle$ Cas9 -/- cyto $c+$ Smac

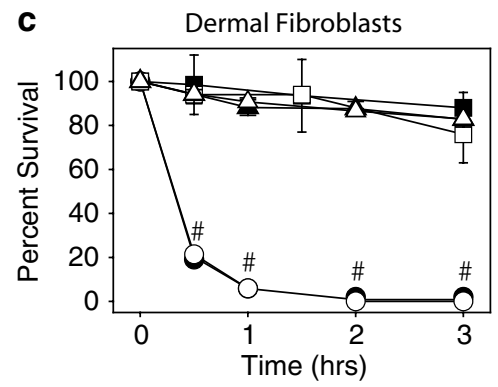

- WT cyto $c$
- WT cyto $c+$ Smac
- Apaf -/- cyto $c$
- - Apaf -/- cyto $c+$ Smac
- Cas 9 -/- cyto $c$
- Cas 9 -/- cyto $c+$ Smac b

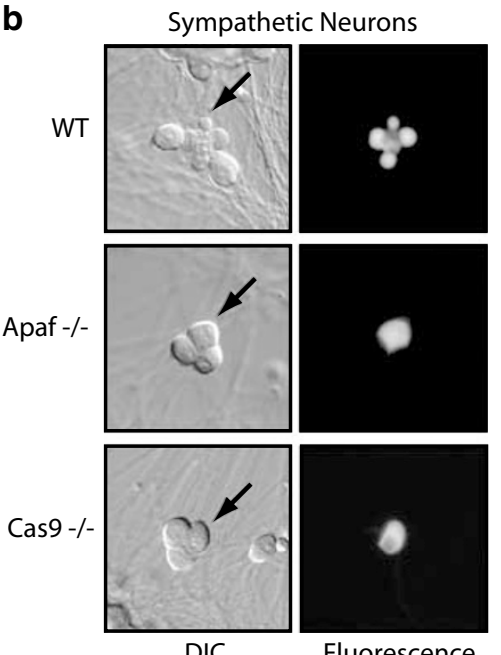

d

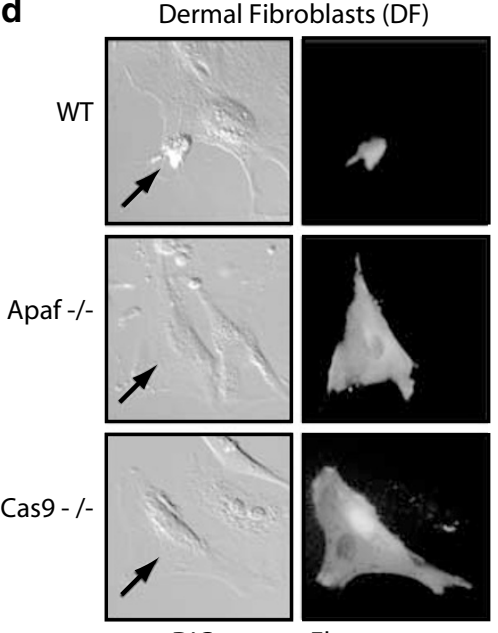

Fluorescence

Figure 2 Genetic deletion of Apaf-1 or Caspase-9 protects sympathetic neurons and dermal fibroblasts from direct activation of the apoptosome. (a) NGF maintained sympathetic neurons $(\mathbf{a}, \mathbf{b})$ and primary dermal fibroblasts $(\mathbf{c}, \mathbf{d})$ from WT, Apaf-1-/- or Caspase-9-/ - mice were cultured for 5 days then injected with either $10 \mathrm{mg} / \mathrm{ml}$ cytochrome $c$ or $10 \mathrm{mg} / \mathrm{ml}$ cytochrome $c+1 \mathrm{mg} / \mathrm{ml} \mathrm{Smac}$. Rhodamine dextran was included to mark the injected cells. Following injection, cell viability was assessed at the indicated time points $(\mathbf{a}, \mathbf{c})$. Data are mean \pm S.E.M. ${ }^{*} P<0.05$ for WT sympathetic neurons injected with cytochrome $c+$ Smac relative to all other conditions. ${ }^{\#} P<0.005$ for WT dermal fibroblasts injected with cytochrome $c$ or cytochrome $c+$ Smac relative to Apaf-1-/- or Caspase-9-/-dermal fibroblasts injected with cytochrome $c$ or cytochrome $c+$ Smac, respectively. Representative DIC photomicrographs (left panels) and fluorescent photomicrographs (right panels) of injected sympathetic neurons (b) and primary dermal fibroblasts (d). Arrows in the DIC images indicate the injected cells

was unable to induce death in the absence of caspase- 3 in sympathetic neurons (Figure $3 \mathrm{a}$ ). These results show that caspase- 3 is the only executioner caspase capable of inducing apoptosis in response to cytochrome $c$ in sympathetic neurons. In contrast, we found that injection of cytochrome $c$ is able to induce apoptosis in caspase-3 deficient fibroblasts, although at a significantly slower rate than observed in fibroblasts isolated from WT littermates (Figure 3b). Whereas greater that $90 \%$ of WT dermal fibroblasts died in response to cytochrome $c$ injection within $1 \mathrm{~h}$, approximately $50 \%$ of caspase 3 null fibroblasts remain viable $2 \mathrm{~h}$ after injection of cytochrome $c$. Interestingly, coinjection of cytochrome $c$ and Smac significantly increased the rate of apoptosis in caspase-3 deficient fibroblasts, indicating that in contrast to WT fibroblasts, caspase-3 deficient fibroblasts are subject to some degree of regulation by IAPs.

To determine if caspase- 7 activation can account for the redundancy with caspase-3 in dermal fibroblasts, we examined caspase activation in cytosolic lysates from WT and caspase-3 deficient fibroblasts that were activated with addition of cytochrome $c$ in vitro. In lysates from WT fibroblasts, addition of mammalian cytochrome $c$ resulted in the cleavage of caspase- 9 , caspase- 3 , and caspase-7 (Figure $3 c$ ). In lysates from caspase-3 deficient fibroblasts, addition of cytochrome $c$ resulted in cleavage of both caspase-9 and caspase-7. Together with our microinjection data, these results indicate caspase-7 is functionally redundant with caspase- 3 in dermal fibroblasts just as seen in the developing cortex. ${ }^{20}$ 

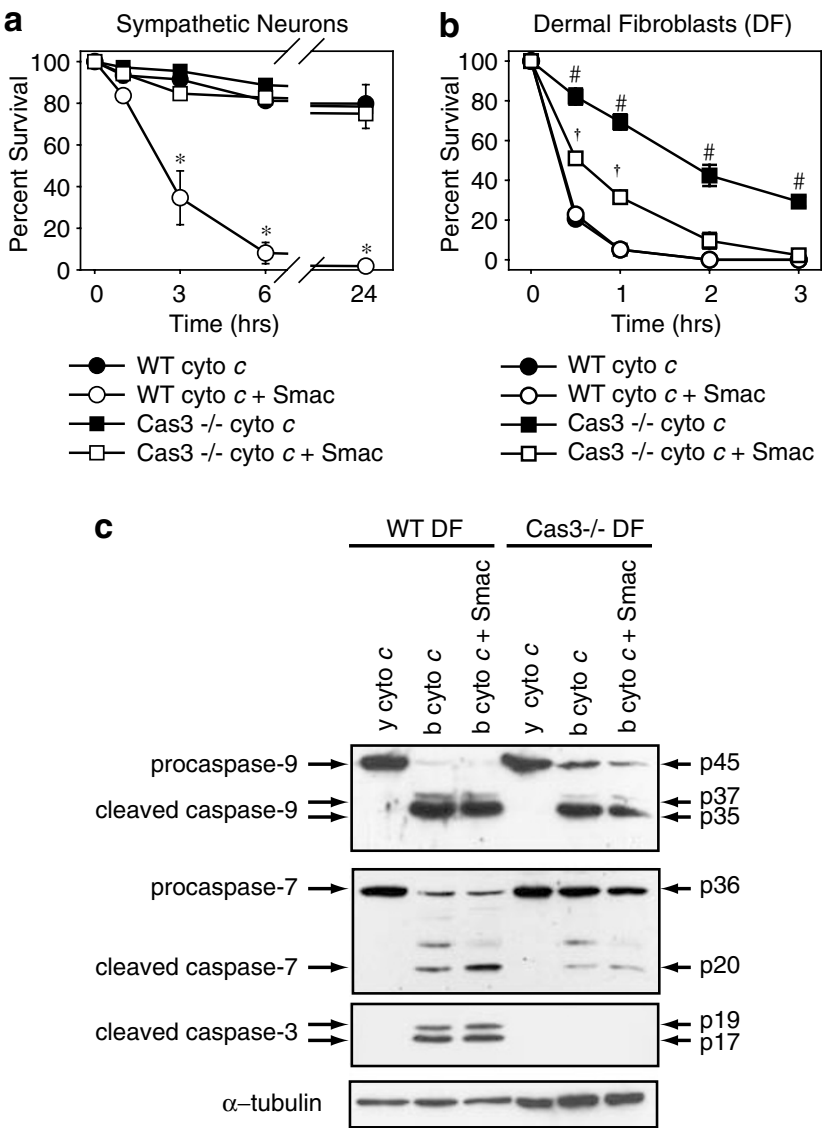

Figure 3 Following direct activation of the apoptosome, genetic deletion of Caspase-3 protects sympathetic neurons, but not dermal fibroblasts. NGF maintained sympathetic neurons (a) and primary dermal fibroblasts (b) were injected with either cytochrome $c$ or cytochrome $c+$ Smac as indicated in legend to Figure 2. Viability of injected cells was assessed at the indicated timepoints. Data are mean \pm S.E.M. ${ }^{\#} P<0.01$ for Caspase-3-1- dermal fibroblasts injected with cytochrome $c$ relative to WT fibroblasts injected with cytochrome $c$ and relative to Caspase-3-I- fibroblasts injected with cytochrome $c+$ Smac. ${ }^{\dagger} P<0.01$ for Caspase-3-/- dermal fibroblasts injected with cytochrome $c+$ Smac relative to WT dermal fibroblasts injected with cytochrome $c+$ Smac. (c) Cytosolic lysates $(150 \mu \mathrm{g})$ from WT primary dermal fibroblasts (WT DF) or Caspase-3-1- primary dermal fibroblasts (Cas3-/- DF) were incubated for $30 \mathrm{~min}$ at $37^{\circ} \mathrm{C}$ with either $10 \mu \mathrm{M}$ yeast cytochrome $c$ (y cyto $c$ ), $10 \mu \mathrm{M}$ bovine cytochrome $c$ (b cyto $c$ ), or $10 \mu \mathrm{M}$ bovine cytochrome $c+1 \mu \mathrm{M}$ Smac (b cyto $c+$ Smac). Caspase activation, indicated by the presence of cleaved caspase products, was detected by western blot using antibodies to Caspase-9, Caspase-7, and Caspase-3. Procaspases and their cleavage products are indicated by arrows

Differential expression of caspase-7 in cortical and sympathetic neurons. To determine why there is no functional redundancy with caspase-3 in sympathetic neurons, we compared the levels of Apaf-1, caspase-9, caspase-3 and caspase-7 in sympathetic neurons, dermal fibroblasts, and cortical neurons isolated from PO mice (Figure 4). We found that procaspase-9 and procaspase-3 proteins were expressed at similar levels in sympathetic neurons, dermal fibroblasts, and cortical neurons. Levels of Apaf-1 in sympathetic neurons were significantly decreased in comparison to the other cell types, consistent with our previous observations indicating that postmitotic sympathetic neurons contain low levels of Apaf-1. ${ }^{29}$ Strikingly,

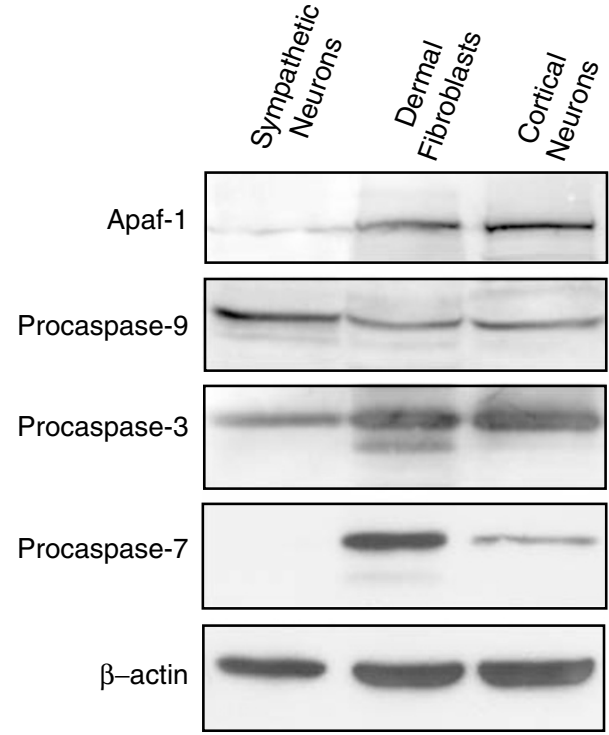

Figure 4 Sympathetic neurons express no detectable levels of Caspase-7 protein compared to primary dermal fibroblasts and cortical neurons. Sympathetic neurons, dermal fibroblasts and cortical neurons were all isolated from the same mice at P0 and maintained in culture for 4 days. Cells were collected in RIPA buffer and equal protein amounts were run on a gel. Proteins were detected with the indicated antibodies

in comparison to dermal fibroblasts and cortical neurons which express a significant amount of procaspase-7, sympathetic neurons expressed virtually undetectable levels of procaspase-7 protein (Figure 4). We also examined caspase-7 expression by semiquantitative PCR and found that caspase-7 mRNA transcripts in sympathetic neurons were markedly reduced in comparison to cortical neurons (Supplementary Figure 1).

We predicted that the lack of significant procaspase-7 protein expression may explain why there is no redundancy at the level of executioner caspases in response to cytochrome $c$ in sympathetic neurons. To test this prediction, we examined whether expression of procaspase-7 would be sufficient to restore the sensitivity of caspase- 3 deficient sympathetic neurons to different apoptotic stimuli. Murine procaspase-7 was cloned from a mouse brain cDNA library and ligated into the pFlag-CMV mammalian expression vector. Expression constructs for GFP along with either procaspase-7 or procaspase-9 (as a control) were microinjected into sympathetic neurons isolated from caspase-3 deficient mice. Following $24 \mathrm{~h}$ to allow for expression, neurons were challenged with an apoptotic stimulus, and the ability of expressing neurons to undergo apoptosis was examined.

When the apoptosome pathway was directly activated with cytosolic injection of cytochrome $c$ and Smac, the expression of procaspase-7 was sufficient to allow caspase-3 deficient sympathetic neurons to undergo apoptosis in a time course nearly identical to WT neurons (Figure 5a). In contrast, overexpression of procaspase-9 did not result in any significant death, indicating that even elevated levels of caspase- 9 are unable to bypass caspase-3 to directly induce death in cytochrome $c$ and 
Smac injected sympathetic neurons. In addition, whereas caspase-3 deficient neurons were unable to undergo apoptosis in response to NGF deprivation, expression of procaspase-7, but not procaspase-9, restored the ability of these neurons to die by apoptosis in response to NGF deprivation (Figure 5b). Expression of procaspase-7 or procaspases-9 alone did not induce death in NGF maintained neurons (data not shown).

As discussed earlier, recent data show that there is functional redundancy between caspase-3 and caspase-7 in immature cortical neurons, which allows caspase-3 deficient cortical neurons to die in response to DNA damage. ${ }^{20} \mathrm{We}$ wanted to compare the ability of postmitotic cortical and sympathetic neurons isolated from the same caspase-3 deficient mice to undergo apoptosis in response to the same apoptotic stimuli. We therefore examined the effect of etoposide, a DNA damaging agent, on these two different neuronal cell types. We found that WT cortical neurons isolated from P0 mice underwent rapid apoptosis in response to the DNA damaging agent etoposide and that deletion of caspase-3 afforded these neurons no protection (Figure 5c). WT sympathetic neurons also underwent apoptosis following treatment with etoposide. In contrast, caspase-3 deficient sympathetic neurons were markedly resistant (Figure $5 d$ ). Here too, the expression of procaspase-7 was sufficient to restore the sensitivity of caspase-3 deficient sympathetic neurons to etoposide.

Taken together, these results demonstrate that in contrast to dermal fibroblasts and cortical neurons, sympathetic neurons do not express any detectable levels of caspase-7. As a consequence, caspase-3 is the only executioner caspase capable of inducing death in sympathetic neurons in response to multiple stimuli that engage the apoptosome pathway.

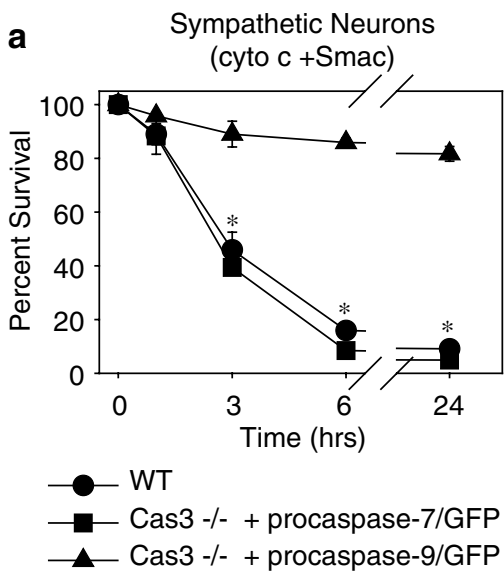

b
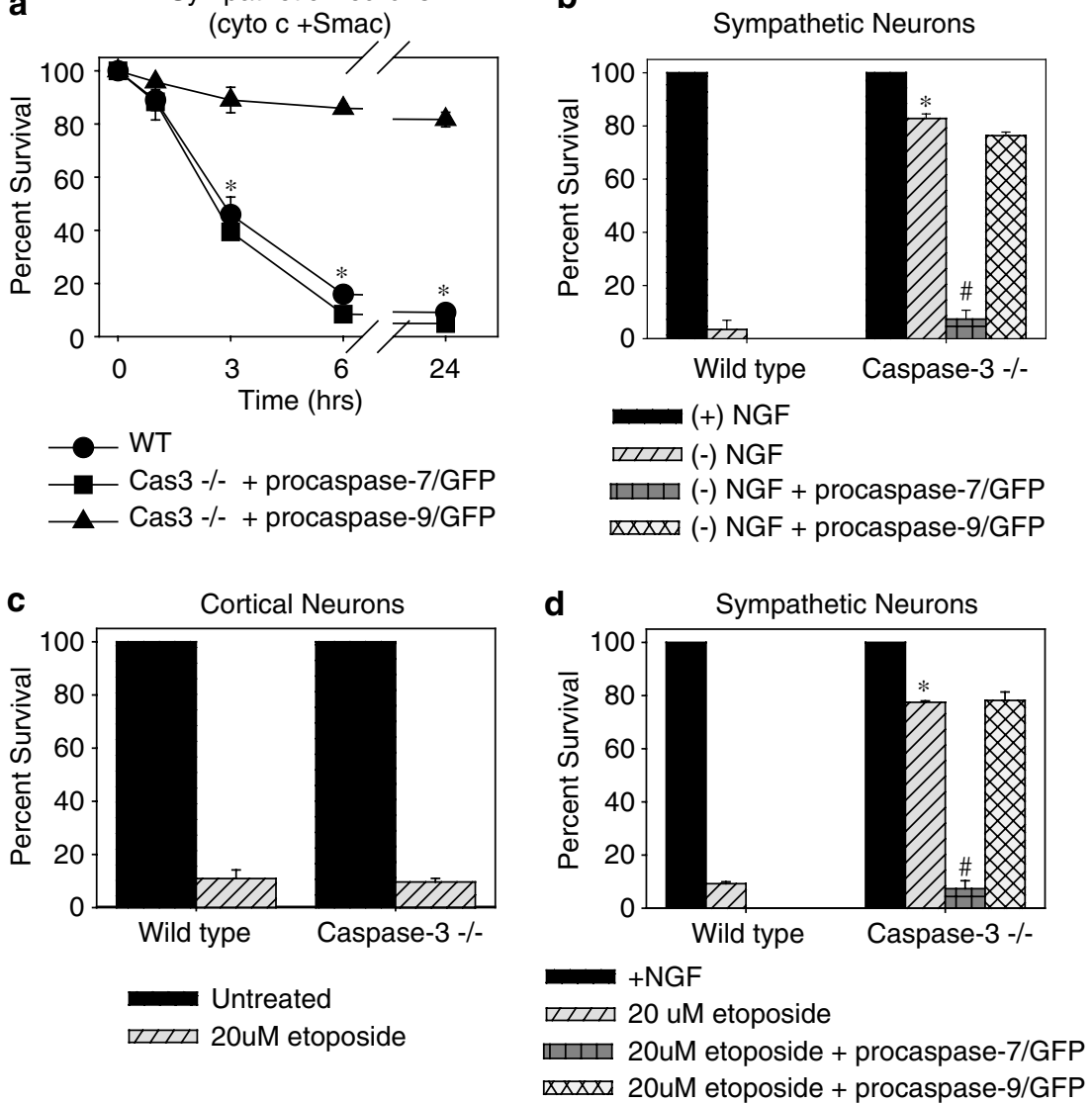

Figure 5 Restoration of Caspase-7 in Caspase-3 deficient sympathetic neurons allows them to undergo apoptosis in response to multiple stimuli. Sympathetic neurons were injected with constructs encoding EGFP $(50 \mathrm{ng} / \mu \mathrm{l}$ ) and $200 \mathrm{ng} / \mu \mathrm{l}$ of either Procaspase-7 or Procaspase-9. (a) Following $24 \mathrm{~h}$, expressing cells (identified as GFP positive) were injected with cytochrome $c(10 \mathrm{mg} / \mathrm{ml})+\mathrm{Smac}(1 \mathrm{mg} / \mathrm{ml})$ and survival was assessed at the indicated time points. Data are mean \pm S.E.M. ${ }^{*} P<0.05$ for both WT and Caspase-3-1- + procaspase-7 relative to Caspase-3-1-+ Procaspase-9. (b) Following $24 \mathrm{~h}$, cells were washed twice and NGF-free media was added. Survival of expressing cells was assessed at $72 \mathrm{~h}$ following NGF deprivation. Data are mean \pm S.E.M. ${ }^{*} P<0.001$ for survival of NGF deprived WT neurons relative to survival of NGF deprived Caspase-3-1- neurons. ${ }^{\#} P<0.001$ for NGF deprived Caspase-3-/- neurons relative to NGF deprived Caspase-3-/- neurons expressing procaspase-7. (c) Cortical neurons were isolated from WT or Caspase-3-1- mice at P0. At 2 days after plating, cortical neurons were treated with $20 \mu \mathrm{M}$ etoposide for $24 \mathrm{~h}$. Cells were stained with Calcein AM dye and 10 random fields were counted for each experimental condition. Cell survival is expressed as a percentage of Calcein AM positive cells in treated conditions divided by the number of Calcein AM positive cells in untreated conditions. (d) Caspase-3-/- sympathetic neurons expressing EGFP and either Procaspase-7 or Procaspase- 9 were treated with $20 \mu \mathrm{M}$ etoposide and survival was assessed at $72 \mathrm{~h}$. Data are mean \pm S.E.M. ${ }^{*} P<0.001$ for survival of NGF deprived WT neurons relative to survival of NGF deprived Caspase-3-/- neurons. ${ }^{\#} P<0.005$ for NGF deprived Caspase-3-/- neurons relative to NGF deprived Caspase-3-/- neurons expressing Procaspase-7 


\section{Discussion}

In this paper, we have examined the role of the apoptosome in regulating apoptosis in primary sympathetic neurons. Using mice genetically deleted for Apaf-1, capsase-9, and caspase3 , we show that these proteins are an integral part of the apoptotic pathway in sympathetic neurons and are required for apoptosis induced by NGF deprivation (Figure 1a, b). Furthermore, we find that deletion of any one of these proteins allows sympathetic neurons to recover from NGF deprivation and survive long-term (Figure 1d). By directly activating the apoptosome in intact cells with microinjection of cytochrome $c$ or by inducing death with etoposide, we have also uncovered an interesting difference in the apoptotic pathway between sympathetic neurons, dermal fibroblasts, and cortical neurons. Whereas caspase- 3 and caspase- 7 are both expressed and functionally redundant in dermal fibroblasts and cortical neurons, sympathetic neurons lack significant expression of caspase-7 (Figure 4). As a result, caspase-3 deficiency alone completely blocks apoptosis in sympathetic neurons but not in dermal fibroblasts or cortical neurons in response to multiple stimuli (Figures 3 and 5). Importantly, the inability of caspase3 deficient sympathetic neurons to undergo apoptosis can be overcome by simply expressing procaspase-7, thereby restoring effector caspase function (Figure 5).

Recently, it has been reported that MEFs derived from mice either deficient for caspase- 9 or doubly deficient for caspase3 and caspase-7 show a delay in cytochrome $c$ release following UV irradiation, implicating a role for caspase feedback at the mitochondria in regulating cytochrome $c$ release. ${ }^{30}$ In contrast, in sympathetic neurons, which are dependent solely on caspase-3 for effector caspase activity, deletion of caspase-3 did not alter the kinetics of cytochrome $c$ release following NGF deprivation (Supplementary Figure 2). These results suggest that the role for caspase-mediated feedback on mitochondrial release of cytochrome $c$ may be cell type or stimulus specific.

A previous report had suggested that the apoptosome pathway becomes important in mediating NGF deprivation induced sympathetic neuronal apoptosis only following genetic deletion of caspase-2. ${ }^{12}$ This was proposed to reconcile the conflicting results where acute inhibition of caspase-2 with antisense reagents protected sympathetic neurons from NGF deprivation, ${ }^{12,14}$ whereas genetic deletion of caspase-2 exhibited no protection. ${ }^{12,15}$ The lack of a phenotype of caspase-2 deficient neurons was attributed to compensatory enablement of the caspase- 9 pathway based on the observation that caspase- 9 and Smac levels were elevated in the absence of caspase- 2 . These results led the authors to conclude that caspase- 2 is the predominant caspase mediating apoptosis after NGF deprivation in sympathetic neurons and that the caspase-9-dependent pathway becomes important only when caspase- 2 is deleted. $^{12}$

Although our data do not exclude a role for caspase-2 in this pathway, our results show that the apoptosome pathway mediated by Apaf-1, caspase- 9 , and caspase- 3 is indeed essential and non-redundant for apoptosis after NGF deprivation in sympathetic neurons. The importance of the cytochrome $c$-dependent apoptosome pathway in executing NGF deprivation induced apoptosis in sympathetic neurons is consistent with several other independent lines of evidence. First, injection of neutralizing antibodies to cytochrome $c^{11}$ or genetic deletion of $\mathrm{Bax}^{31}$ is sufficient to block apoptotic death. Second, this neuronal death is inhibited by the expression of dominant-negative constructs to caspase- 9 and caspase- $3 .{ }^{13}$ Third, overexpression of XIAP, which selectively binds and inhibits caspases- $9,-3$, and $-7,,^{32,33}$ but not caspase- $2,{ }^{34,35}$ also prevents NGF deprivation induced apoptosis in these neurons. $^{36}$

The ability of Apaf-1, caspase- 9 , or caspase- 3 deficient sympathetic neurons to recover after the point of cytochrome $c$ release and survive long term upon readdition of NGF is striking (Figure 1c, d). These results contrast the observations in many mitotic cells, where cells arrested after cytochrome $c$ release by caspase inhibition or deletion of Apaf-1 or caspase9 fail to recover even when trophic factors are restored. ${ }^{22-24}$ The recoverability of sympathetic neurons is dependent on the timely restoration of trophic support, as the commitment point for death in sympathetic neurons in which apoptosis is arrested with caspase inhibition does not correspond with cytochrome $c$ release, but rather with the subsequent loss of mitochondrial membrane potential. ${ }^{25,37}$ In the prolonged absence of trophic support, however, sympathetic neurons arrested after cytochrome $c$ release eventually undergo nonapoptotic death due to metabolic failure. ${ }^{38,39}$ Consistent with this observation, in the absence of adequate NGF, caspase-3 deficient neurons from sympathetic ganglia undergo developmental death in vivo, but with minimal DNA fragmentation and nuclear and cytoplasmic morphology that is distinct from that observed in apoptotic cells. ${ }^{40}$ Thus, while our results show that apoptosis does not occur in sympathetic neurons in the absence of caspase-3, developmental programmed cell death can still proceed, albeit without apoptotic morphology, in the caspase-3 deficient mice in vivo.

Taken together with our previous data, these results show that sympathetic neurons have developed multiple mechanisms that provide increased postcytochrome $c$ control of apoptosis. First, by having reduced levels of Apaf-1, sympathetic neurons engage a strict regulation of caspase activation by endogenous XIAP. ${ }^{29}$ Second, these neurons have the unique capacity to recover when the apoptotic pathway is arrested even after cytochrome $c$ release. Third, the lack of significant caspase-7 expression in sympathetic neurons results in a non-redundant pathway that is dependent on caspase-3 alone for effector caspase function.

While the core components of the apoptotic machinery are highly conserved, the fine tuning of this pathway by diverse regulatory mechanisms could be reflective of the different requirements of apoptosis in different cell types. For example, sympathetic neurons undergo extensive apoptosis during development in order to shape and refine the nervous system. However, once this developmental period is over, surviving neurons must last long term. These additional mechanisms of regulation would allow the postmitotic sympathetic neurons to effectively maintain this balance between life and death.

\section{Materials and Methods}

Knock-out mice and cell culture. Apaf- 1 deficient mice were generated by Joachim Herz ${ }^{21}$ (UT Southwestern) and were kindly provided by the laboratory of 
Dr. Susan Ackerman (Jackson Laboratory). Caspase-9 and caspase-3 deficient mice were generated by Dr. Keisuke Kuida and were kindly provided by the laboratory of Dr. Kevin Roth (University of Alabama). These mice were backcrossed into the C57BL6 background for at least 7-10 generations.

Primary dermal fibroblasts were isolated from PO WT, Apaf-/-, caspase-9-1and caspase-3-/- mice. The dorsal skin was removed, minced and rinsed in ice cold PBS. Tissue was incubated for $1 \mathrm{~h}$ with $1 \mathrm{mg} / \mathrm{ml}$ collagenase, followed by digestion with $2.5 \mathrm{mg} / \mathrm{ml}$ trypsin for $1 \mathrm{~h}$ at $37^{\circ} \mathrm{C}$. Tissue was then passaged through a 25-gauge needle until a single-cell suspension was obtained. Cells were plated in DMEM with $10 \% \mathrm{FBS}, 100 \mathrm{mg} / \mathrm{ml}$ penicillin, and $100 \mathrm{mg} / \mathrm{ml}$ streptomycin.

Primary sympathetic neurons were isolated as described previously. ${ }^{9}$ Briefly, superior cervical ganglia were dissected from PO mice and treated with $1 \mathrm{mg} / \mathrm{ml}$ collagenase, followed by $2.5 \mathrm{mg} / \mathrm{ml}$ trypsin for $30 \mathrm{~min}$ each at $37^{\circ} \mathrm{C}$. Cells were then dissociated by passaging through a fire-polished pipet and plated on collagencoated dishes in MEM with Earle's salts supplemented with $50 \mathrm{ng} / \mathrm{ml} \mathrm{NGF,} 10 \%$ FBS, $2 \mathrm{mM}$ glutamine, $100 \mu \mathrm{g} / \mathrm{ml}$ penicillin, $100 \mu \mathrm{g} / \mathrm{ml}$ streptomycin, $20 \mu \mathrm{M}$ flourodeoxyuridine, $20 \mu \mathrm{M}$ uridine, and $3.3 \mu \mathrm{g} / \mathrm{ml}$ aphidicolin.

Cortical neurons were isolated from P0 mice. The cortex was isolated and the ganglionic eminence and menengies were removed. The cortex was minced in ice cold HBSS without calcium and magnesium and placed in $5 \mathrm{ml}$ dissociation media $\left(80 \mathrm{mM} \mathrm{Na}_{2} \mathrm{SO}_{4}, 30 \mathrm{mM} \mathrm{K}_{2} \mathrm{SO}_{4}, 5.8 \mathrm{mM} \mathrm{MgCl}_{2}, 250 \mu \mathrm{M} \mathrm{CaCl}_{2}, 1 \mathrm{mM}\right.$ HEPES, $20 \mathrm{mM}$ glucose, $200 \mu \mathrm{M} \mathrm{NaOH}, 0.5 \%$ phenol red). Tissue was then gently digested with $100 \mathrm{U}$ of papain for $40 \mathrm{~min}$ at $37^{\circ} \mathrm{C}$. Tissue was rinsed with dissociation media containing $10 \mathrm{mg} / \mathrm{ml}$ bovine serum albumin and $10 \mathrm{mg} / \mathrm{ml}$ soybean trypsin inhibitor. Cells were dissociated to a single-cell suspension and plated on poly-D-lysine/ laminin coated plates at a density of $1 \times 10^{6}$ per $35 \mathrm{~mm}$ dish in Neurobasal A containing N2 supplement, $5 \% \mathrm{FBS}, 20 \mathrm{mM}$ glutamine, $100 \mathrm{mg} / \mathrm{ml}$ penicillin, and $100 \mathrm{mg} / \mathrm{ml}$ streptomycin.

Cell treatments. Survival of sympathetic neurons following NGF withdrawal was conducted as described previously. ${ }^{9}$ Briefly, P0 sympathetic neurons were maintained in NGF containing media for 4-5 days, following which the cells were washed twice with NGF-free media and incubated in NGF-free media containing anti-NGF blocking antibody. Cell survival was assessed at multiple time points following NGF withdrawal by morphology, with cells that had intact, phase-bright cell bodies scored as alive. At least 75-150 neurons were counted for each condition. This morphological criteria of assessing cell death correlates well with other assays of cell death ${ }^{27}$ For the recoverability assay, cells were deprived of NGF for $24-36 \mathrm{~h}$, following which they were incubated in NGF containing media for 7 days. ${ }^{25}$ Cell survival was determined by the percentage of cells with intact healthy phase bright bodies following 7 days of NGF addition.

For DNA damage experiments, cortical neurons were plated on $35 \mathrm{~mm}$ dishes for 2 days, following which they were treated with $20 \mathrm{uM}$ etoposide for $24 \mathrm{~h}$. To assess cell survival, cells were washed twice with PBS and incubated with $25 \mathrm{uM}$ Calcein AM for 20 min. Following incubation, Calcein AM positive cells were counted in 10 random fields at $\times 20$ magnification. Cell survival was represented as the percentage of Calcein AM positive cells in the treated condition as compared to the untreated condition.

Microinjections. Cells were plated on $35 \mathrm{~mm}$ dishes and microinjected with needles pulled on a Flaming-Brown horizontal micropipette puller (Sutter Instruments) using a Narashigi micromanipulator mounted on a Leica inverted florescent microscope. Between 50 and 100 cells were injected in each experiment. The microinjection buffer contained $100 \mathrm{mM} \mathrm{KCl}$ and $10 \mathrm{mM} \mathrm{KP}$, pH 7.4. For injections involving plasmid DNA, sympathetic neurons were injected 4 days after plating and allowed $24 \mathrm{~h}$ to express plasmid DNA prior to experimentation. DNA microinjections contained $50 \mathrm{ng} / \mu \mathrm{l}$ enhanced GFP (Clontech) and $200 \mathrm{ng} / \mu \mathrm{l}$ of indicated plasmid. Cytochrome $c$ microinjections contained $5 \mathrm{mg} / \mathrm{ml}$ rhodamine dextran to mark injected cells and $10 \mathrm{mg} / \mathrm{ml}$ cytochrome $c$. Where indicated, $1 \mathrm{mg} / \mathrm{ml}$ recombinant Smac protein was injected along with $10 \mathrm{mg} / \mathrm{ml}$ cytochrome $c$. Following injections, viable cells were identified as rhodamine positive and having intact, phase-bright cell bodies.

Immunofluorescence analysis. The status of cytochrome $c$ (whether intact in the mitochondrial or released) was examined by immunofluorescence. Briefly, sympathetic neurons were cultured for 4 days in the presence of NGF, following which they were left untreated or deprived of NGF for $24 \mathrm{~h}$. NGF maintained and deprived neurons were fixed in $4 \%$ paraformaldehyde and incubated overnight in anticytochrome $c$ primary antibody (556432, BD Biosciences) followed by a $2 \mathrm{~h}$ incubation with anti-mouse Cy3 secondary antibody (Jackson Labs). Nuclei were stained with Hoechst 33258 (Molecular Probes).

Preparation of cytosolic extracts for caspase activation assays. Dermal fibroblasts from WT and caspase-3 knockout mice were washed once in ice-cold PBS and harvested by scraping. The resulting cell pellet was resuspended in three volumes of hyptonic buffer (10 mM HEPES, $\mathrm{pH} 7.5$, $10 \mathrm{mM} \mathrm{KCl}, 0.5 \mathrm{mM}$ EDTA, $1 \mathrm{mM}$ EGTA, $1 \mathrm{mM} \mathrm{MgCl}, 1 \mathrm{mM} \mathrm{DTT}$ ) and tumbled for $20 \mathrm{~min}$ at $4^{\circ} \mathrm{C}$. Cells were lysed by passaging through a 25 -gauge needle and centrifuged for $30 \mathrm{~min}$ at $16000 \times \mathrm{g}$ to remove nuclei and heavy membrane fractions. The supernatant was then centrifuged for $30 \mathrm{~min}$ at $100000 \times \mathrm{g}$ to remove the light membrane fraction, and the resulting cytosolic supernatant was used for caspase activation assays.

In vitro caspase activation assays were performed by incubating equal protein $(150 \mu \mathrm{g})$ of cytosolic lysate with $1 \mathrm{mM}$ dATP and $10 \mathrm{mM}$ cytochrome $c$ in oligimerization buffer ( $25 \mathrm{mM}$ HEPES, $\mathrm{pH} 7.5,50 \mathrm{mM} \mathrm{NaCl}, 10 \mathrm{mM} \mathrm{KCl}, 1.5 \mathrm{mM}$ $\mathrm{MgCl}_{2}, 10 \%$ glycerol, $1 \mathrm{mM} \mathrm{DTT}$ ) in a final volume of $100 \mu \mathrm{l}$ at $37^{\circ}$ for $90 \mathrm{~min}$.

Western blot. Western Blots were performed as described previously. ${ }^{27}$ Primary antibodies were as follows: anti-Apaf-1 (13F11, Alexis biochemicals); antiprocaspase-3 (9665, Cell Signaling); anti-cleaved caspase-3 (9661, Cell Signaling); anti-caspase-7 (9492, Cell Signaling); anti-caspase-9 (M0543, MBL International Corporation); anti- $\alpha$ Tubulin (T9026, Sigma); anti- $\beta$-actin (A5316, Sigma). HRPconjugated secondary antibodies were purchased from Pierce Chemical Co. Proteins were detected using ECL-Plus (Amersham Biosciences).

Cloning and detection of mouse procaspase-7. Mouse procaspase-7 was cloned using a mouse brain CDNA library as template. The forward primer (5'-CCCAAGCTTATGACCGATGATCAGGAC- $3^{\prime}$ ) included a $5^{\prime}$ Hind III site and the reverse primer $\left(5^{\prime}\right.$-CGGGATCCTCAACGGCTGAAGTAC-3') included a $3^{\prime}$ $B a m H I$ site. The resulting amplification product was digested and cloned into pCMV FLAG (Sigma). The sequence of the resulting transformants was verified and protein expression of procaspases-7 was verified by Western blot of 293 cells transfected with the construct. Detection of endogenous procaspase-7 and GAPDH was performed by isolating RNA from sympathetic neurons and cortical neurons that had been maintained in culture for 4 days. RNA was used to construct CDNA libraries, and $2 \mu \mathrm{l}$ of cDNA was used as a template in a PCR assay $\left(95.0^{\circ} \mathrm{C}\right.$ for $1 \mathrm{~min}, 55.5^{\circ} \mathrm{C}$ for $1 \mathrm{~min}, 72.0^{\circ} \mathrm{C}$ for $\left.1 \mathrm{~min}\right)$. Multiple cycles were run to ensure that bands were in the linear range of detection. The primers used were:

\section{Caspase-7 Fwd: $\quad$ 5'-GAGGACCACAGCAACTCG-3' Caspase-7 Rev: $\quad 5^{\prime}$-CACCGGGATCTTGTTGC-3' GAPDH Fwd: $\quad 5^{\prime}$-CCATGGAGAAGGTGGGG-3' GAPDH Rev: $\quad$ 5'-CAAAGTTGTCATGGATGACC-3'}

Genotyping. Tails were digested in proteinase $\mathrm{K}$ for $1 \mathrm{~h}$ at $55^{\circ}$ and genomic DNA was isolated using the DNeasy Tissue Kit (Qiagen). Primers and PCR conditions for knockout lines are as follows:

Apaf-1: Fwd WT: 5'-GCCTGCCATCCCATAGATGGT-3 Fwd KO: 5'-GATTGGGAAGACAATAGCAGG-3' Rev (common): 5'-CAGCAAGGCCTTTACCTGTTG-3' WT: 900 bp; Apaf-1 KO: 600 bp

Caspase-9: Fwd WT: 5'-AGGCCAGCCACCTCCAGTTCC-3' Rev WT: 5'-CAGAGATGTCGAGAGAAGCCCACT-3' Fwd KO: 5'-AGATAGAGCACTCACATATGC-3' Rev KO: 5'-TGCTAAAGCGCATGCTCCAGACTG-3' WT: 250 bp; Caspase-9 KO: 450 bp

Caspase-3: Fwd (common): 5'-GCGAGTGAGAATGTGCATAAATTC-3' Rev WT: 5'-GGGAAACCAACAGTACTCAGTCCT-3' Rev KO: 5'-TGCTAAAGCGCATGCTCCAGACTG-3' WT: 350 bp; Caspase-3 KO: 300 bp 
Statistic analysis. Statistic analysis of data was performed using Prism 4 (GraphPad Software). All statistical analysis was performed using the Student's $t$-test with confidence intervals of $99 \%$.

Acknowledgements. We thank Michelle Smith and Yolanda Huang for critical review of this manuscript. This work was supported by National Institutes of Health Grants NS42197 (to MD) and NS049745 (to KMW). We apologize that we were unable to cite all relevant work due to the limit on the number of references permissible.

1. Danial NN, Korsmeyer SJ. Cell death: critical control points. Cell 2004; 116: 205-219.

2. Buss RR, Sun W, Oppenheim RW. Adaptive roles of programmed cell death during nervous system development. Annu Rev Neurosci 2006; 29: 1-35.

3. Stennicke HR, Salvesen GS. Caspases-controlling intracellular signals by protease zymogen activation. Biochim Biophys Acta 2000; 1477: 299-306.

4. Riedl SJ, Shi Y. Molecular mechanisms of caspase regulation during apoptosis. Nat Rev Mol Cell Biol 2004; 5: 897-907.

5. Boatright KM, Salvesen GS. Mechanisms of caspase activation. Curr Opin Cell Biol 2003 15: $725-731$.

6. Wang X. The expanding role of mitochondria in apoptosis. Genes Dev 2001; 15: 2922-2933.

7. Salvesen GS, Duckett CS. IAP proteins: blocking the road to death's door. Nat Rev Mol Cell Biol 2002; 3: 401-410.

8. Deshmukh M, Johnson Jr EM. Programmed cell death in neurons: focus on the pathway of nerve growth factor deprivation-induced death of sympathetic neurons. Mol Pharm 1997 51: 897-906.

9. Deshmukh M, Vasilakos J, Deckwerth TL, Lampe PA, Shivers BD, Johnson Jr EM. Genetic and metabolic status of NGF-deprived sympathetic neurons saved by an inhibitor of ICEfamily proteases. J Cell Biol 1996; 135: 1341-1354.

10. Troy CM, Stefanis L, Prochiantz A, Greene LA, Shelanski ML. The contrasting roles of ICE family proteases and interleukin- $\beta$ in apoptosis induced by trophic factor withdrawal and by copper/zinc superoxide dismutase down-regulation. Proc Natl Acad Sci USA 1996; 93 $5635-5640$

11. Neame SJ, Rubin LL, Philpott KL. Blocking cytochrome $c$ activity within intact neurons inhibits apoptosis. J Cell Biol 1998; 142: 1583-1593.

12. Troy CM, Rabacchi SA, Hohl JB, Angelastro JM, Greene LA, Shelanski ML. Death in the balance: alternative participation of the caspase-2 and -9 pathways in neuronal death induced by nerve growth factor deprivation. J Neurosci 2001; 21: 5007-5016.

13. Yu LY, Jokitalo E, Sun YF, Mehlen P, Lindholm D, Saarma M et al. GDNF-deprived sympathetic neurons die via a novel nonmitochondrial pathway. J Cell Biol 2003; 163: 987-997.

14. Troy CM, Stefanis L, Greene LA, Shelanski ML. Nedd2 is required for apoptosis afte trophic factor withdrawal, but not superoxide dismutase (SOD1) downregulation, in sympathetic neurons and PC12 cells. J Neurosci 1997; 17: 1911-1918.

15. Bergeron L, Perez Gl, Macdonald G, Shi L, Sun Y, Jurisicova A et al. Defects in regulation of apoptosis in caspase-2-deficient mice. Genes Dev 1998; 12: 1304-1314.

16. O'Reilly LA, Ekert $P$, Harvey N, Marsden V, Cullen L, Vaux DL et al. Caspase-2 is not required for thymocyte or neuronal apoptosis even though cleavage of caspase-2 is dependent on both Apaf-1 and caspase-9. Cell Death Differ 2002; 9: 832-841.

17. Roth KA, D'Sa C. Apoptosis and brain development. Ment Retard Dev Disabil Res Rev 2001; 7: 261-266.

18. Zheng TS, Flavell RA. Divinations and surprises: genetic analysis of caspase function in mice. Exp Cell Res 2000; 256: 67-73.

19. Leonard JR, Klocke BJ, D'Sa C, Flavell RA, Roth KA. Strain-dependent neurodevelopmental abnormalities in caspase-3-deficient mice. J Neuropathol Exp Neurol 2002; 61: 673-677.
20. Houde C, Banks KG, Coulombe N, Rasper D, Grimm E, Roy S et al. Caspase-7 expanded function and intrinsic expression level underlies strain-specific brain phenotype of caspase3-null mice. J Neurosci 2004; 24: 9977-9984.

21. Honarpour N, Du C, Richardson JA, Hammer RE, Wang X, Herz J. Adult Apaf-1-deficient mice exhibit male infertility. Dev Biol 2000; 218: 248-258.

22. McCarthy NJ, Whyte MK, Gilbert CS, Evan GI. Inhibition of Ced-3/ICE-related proteases does not prevent cell death induced by oncogenes, DNA damage, or the Bcl-2 homologue Bak. J Cell Biol 1997; 136: 215-227.

23. Brunet CL, Gunby RH, Benson RS, Hickman JA, Watson AJ, Brady G. Commitment to cell death measured by loss of clonogenicity is separable from the appearance of apoptotic markers. Cell Death Differ 1998; 5: 107-115.

24. Ekert PG, Read SH, Silke J, Marsden VS, Kaufmann H, Hawkins CJ et al. Apaf-1 and caspase-9 accelerate apoptosis, but do not determine whether factor-deprived or drugtreated cells die. J Cell Biol 2004; 165: 835-842.

25. Deshmukh M, Kuida K, Johnson Jr EM. Caspase inhibition extends the commitment to neuronal death beyond cytochrome $\mathrm{c}$ release to the point of mitochondrial depolarization. J Cell Biol 2000; 150: 131-143.

26. Putcha GV, Harris CA, Moulder KL, Easton RM, Thompson CB, Johnson Jr EM. Intrinsic and extrinsic pathway signaling during neuronal apoptosis: lessons from the analysis of mutant mice. J Cell Biol 2002; 157: 441-453.

27. Potts PR, Singh S, Knezek M, Thompson CB, Deshmukh M. Critical function of endogenous XIAP in regulating caspase activation during sympathetic neuronal apoptosis. J Cell Biol 2003; 163: 789-799.

28. Deshmukh M, Du C, Wang X, Johnson Jr EM. Exogenous smac induces competence and permits caspase activation in sympathetic neurons. J Neurosci 2002; 22: 8018-8027.

29. Wright KM, Linhoff MW, Potts PR, Deshmukh M. Decreased apoptosome activity with neuronal differentiation sets the threshold for strict IAP regulation of apoptosis. $J$ Cell Biol 2004; 167: 303-313.

30. Lakhani SA, Masud A, Kuida K, Porter Jr GA, Booth CJ, Mehal WZ et al. Caspases 3 and 7: key mediators of mitochondrial events of apoptosis. Science 2006; 311: 847-851.

31. Deckwerth TL, Elliott JL, Knudson CM, Johnson Jr EM, Snider WD, Korsmeyer SJ. Bax is required for neuronal death after trophic factor deprivation and during development. Neuron 1996; 17: 401-411.

32. Shiozaki EN, Chai J, Rigotti DJ, Riedl SJ, Li P, Srinivasula SM et al. Mechanism of XIAPmediated inhibition of caspase-9. Mol Cell 2003; 11: 519-527.

33. Scott FL, Denault JB, Riedl SJ, Shin H, Renatus M, Salvesen GS. XIAP inhibits caspase-3 and -7 using two binding sites: evolutionarily conserved mechanism of IAPs. EMBO J 2005; 24: $645-655$

34. Ho PK, Jabbour AM, Ekert PG, Hawkins CJ. Caspase-2 is resistant to inhibition by inhibito of apoptosis proteins (IAPS) and can activate caspase-7. FEBS J 2005; 272: 1401-1414.

35. Wilkinson JC, Wilkinson AS, Scott FL, Csomos RA, Salvesen GS, Duckett CS. Neutralization of Smac/Diablo by inhibitors of apoptosis (IAPs). A caspase-independent mechanism for apoptotic inhibition. J Biol Chem 2004; 279: 51082-51090.

36. Yu LY, Korhonen L, Martinez R, Jokitalo E, Chen Y, Arumae U et al. Regulation of sympathetic neuron and neuroblastoma cell death by XIAP and its association with proteasomes in neural cells. Mol Cell Neurosci 2003; 22: 308-318.

37. Martinou I, Desagher S, Eskes R, Antonsson B, Andre E, Fakan S et al. The release of cytochrome $c$ from mitochondria during apoptosis of NGF-deprived sympathetic neurons is a reversible event. J Cell Biol 1999; 144: 883-889.

38. Chang LK, Schmidt RE, Johnson Jr EM. Alternating metabolic pathways in NGF-deprived sympathetic neurons affect caspase-independent death. J Cell Biol 2003; 162: 245-256.

39. Xue L, Fletcher GC, Tolkovsky AM. Autophagy is activated by apoptotic signalling in sympathetic neurons: an alternative mechanism of death execution. Mol Cell Neurosci 1999; 14: 180-198.

40. Oppenheim RW, Flavell RA, Vinsant S, Prevette D, Kuan CY, Rakic P. Programmed cell death of developing mammalian neurons after genetic deletion of caspases. $J$ Neurosci 2001; 21: 4752-4760.

\section{Supplementary Information accompanies the paper on Cell Death and Differentiation website (http://www.nature.com/cdd)}

